\title{
Modeling and analysis of pelletization process based on a multi-hole pelletizing device
}

\author{
Qinghai Jiang, Kai Wu*, Yu Sun \\ (School of Mechanical Engineering, Nanjing University of Science and Technology, Nanjing 210094, China)
}

\begin{abstract}
A multi-hole pelletizing device (MPD) was proposed to simulate the granular extrusion process of animal feed due to its cheap, fast, and controllable features. The compression mechanism was analyzed and discussed according to the compression force-time curve. This study applied response surface methodology (RSM) with a central composite design (CCD) to develop predictive models for the compression force $F_{\text {out }}$ and the pellet properties which includes pellet density $\rho_{\mathrm{p}}$, pellet moisture content $M_{\mathrm{cp}}$, and pellet tensile strength $D_{\mathrm{p}}$ based on the MPD. The effects of feedstock moisture content $M_{\mathrm{cf}}$ (10\%-18\% w.b.), feedstock particle size $S_{\mathrm{f}}\left(8\right.$ meshes -24 meshes), die temperature $T_{\mathrm{d}}\left(70^{\circ} \mathrm{C}-110^{\circ} \mathrm{C}\right)$ and compression speed $V_{\mathrm{c}}$ ( $5 \mathrm{~mm} / \mathrm{min}$ to $25 \mathrm{~mm} / \mathrm{min}$ ) were investigated. Response surface models developed for the compression force and pellet properties have adequately described the pelleting process $\left(R^{2}>0.95\right)$. The results showed the significant effects of all factors and most of the squared and interaction terms on the compression force and pellet physical properties. It can be concluded from the present study that moisture content and die temperature, followed by compression speed and feedstock particle size are the interacting process factors influencing compression force and pellet properties.
\end{abstract}

Keywords: animal feed, pelletization, modeling, compression force, response surface methodology, analysis of variance DOI: $10.25165 /$ j.ijabe.20191201.3264

Citation: Jiang Q H, Wu K, Sun Y. Modeling and analysis of pelletization process based on a multi-hole pelletizing device. Int J Agric \& Biol Eng, 2019; 12(1): 17-23.

\section{Introduction}

Feed constitutes up to $60 \%-70 \%$ of the total cost for commercially reared broilers ${ }^{[1,2]}$. As the primary feed form for poultry rearing, pellets have been used extensively in the world ${ }^{[3-5]}$. Compared with the mash feeds, pelleted animal feeds have the following advantages: more consistent size and higher bulk density, better flow property and thus improved ease of handling and transportation, decreased ingredient segregation and less dust formation during processing and thus less feed wastage, improved palatability and animal performance ${ }^{[4-8]}$. However, there are several problems with pelleted animal feeds, including high energy consumption and unstable product quality during the feed pelletization process. Therefore, it is important to study the effects of processing parameters on the feed pelletization process, so as to find the optimal conditions for the process, and finally achieve higher pellet quality and lower production costs.

Previous research studies on feed pelletization have focused on the establishment of a cost-competitive process with high pellet quality and low energy consumption ${ }^{[1,8-11]}$. The pelletization process is complex, as the quality and energy consumption depend on the ingredient and mechanical properties of feedstock, the steam conditioning temperature, and the ring die size ${ }^{[12-15]}$. The chemical composition and physical properties of feedstock can vary greatly because of the differences in varieties, cultivation

\section{Received date: 2017-02-20 Accepted date: 2018-12-04}

Biographies: Qinghai Jiang, $\mathrm{PhD}$, research interests: modern agricultural technology and equipment, Email: jiangqinghai101@126.com; Yu Sun, PhD, Professor, research interests: advanced manufacturing technology and equipment, Email: sunyu@mail.njust.edu.cn.

*Corresponding author: Kai Wu, PhD, Professor, research interests: advanced manufacturing technology and equipment, School of Mechanical Engineering, Nanjing University of Science and Technology, Nanjing 210094, China. Tel: +86-25-84315612, Email: wukai@njust.edu.cn. conditions and additives. Additives, such as fat, can act as lubricants to decrease the friction between the feedstock and the die wall $^{[16,17]}$. The compaction characteristics of different animal feedstock have been examined in various studies ${ }^{[4,8,9,18]}$. Compared to industry experiment with high costs and difficulty of operation, single pellet press is cheap and fast, and can be operated easily and independently ${ }^{[19]}$. As a simple method to investigate the material's mechanical properties during the densification process, the single pellet press method has been widely used for parameter optimization in recent years ${ }^{[6,20-22]}$. Significant work for understanding the information from a single pellet press was carried out by Holm et al. ${ }^{[12,23]}$ The pelleting pressure depends on the material properties and processing temperature in a single press, and increases exponentially with the press channel length ${ }^{[24]}$. The single pellet press method clarifies the compressibility of the pellet and allows for the evaluation of quality properties, such as density and tensile strength, in a simple and inexpensive manner.

However, single pellet studies have their challenges in providing process data with relevance for industrial applications of ring die pelletizing. When Mišljenović et al. ${ }^{[25]}$ compared the pellets produced by a single pellet press and a ring die pellet mill, obvious differences in pellet quality were observed between the two pelleting methods. With the single pellet press, materials were compressed directly with transversal fiber orientation by a press piston in a press channel. In contrast, the conic fiber orientation could be observed in a pellet by the ring die pellet mill. The difference was caused by the liquidity of material and the friction between the material and channel wall. In addition, the materials were compressed in both the longitudinal and radial direction when they were pressed into the press channel at the entrance with chamfering. The effects of chamfering and opening ratio are seldom considered for the single pellet press. The single pellet press with a specified pressure has essential differences with the "real life" pellet mill. Rather than being designated, the 
pressure of the pellet mill is connected and dependent on the process factors such as the feedstock component, moisture content, press channel length, etc. Therefore, a multi-hole pelletizing device (MPD) consisting of a piston, a multi-hole die, and a tube was proposed to simulate the pelleting process. With this device, the compression pressure required to force the material flow into press channels was investigated. The MPD was used to analyze the effects of raw material properties and processing parameters on the compression pressure and pellet properties, so as to increase the understanding of the connection between the animal feed properties and these processing factors.

\section{Materials and methods}

\subsection{Experimental setup}

The MPD experimental system designed for pelleting consisted of a piston, a cylindrical tube, and a multi-hole die with diameters of $39.9 \mathrm{~mm}, 40 \mathrm{~mm}$, and $39.9 \mathrm{~mm}$, respectively. The multi-hole die had seven press channels that were $3.8 \mathrm{~mm}$ diameter holes drilled through a cylindrical steel die. The multi-hole die had press channels of $38 \mathrm{~mm}$ in length and chamfer angle of $45^{\circ}$ at

the entrance of channels. The multi-hole die was located in the tube by a metal ring and assembled at the end of the tube. The apparatus was mounted on a universal testing machine that was used to apply an external load to a pressing piston at a certain speed The compression force $\left(F_{\text {out }}\right)$ applied could be measured by the universal testing machine. The MPD was equipped with six heaters of $400 \mathrm{~W}$ around the tube to heat the MPD and feedstock during pelleting. The temperature was controlled by a digital controller. A series of mesh sieves were used to distinguish the feedstock particle size. The MPD experimental system is shown in Figure 1. Although the MPD cannot represent all aspects of a real industrial pellet mill, it can give an indication of how the process parameters affect the compression force and the pellet quality in press channels. In addition, some process parameters such as temperature and friction are connected and dependent on each other in the industrial pellet mill. By contrast, the process parameters are easier to adjust in a MPD. Therefore, the experimental results obtained with a MPD will be useful and referenced for process adjustments, reducing energy consumption, and the improvement of pellet quality during industrial pelletizing.

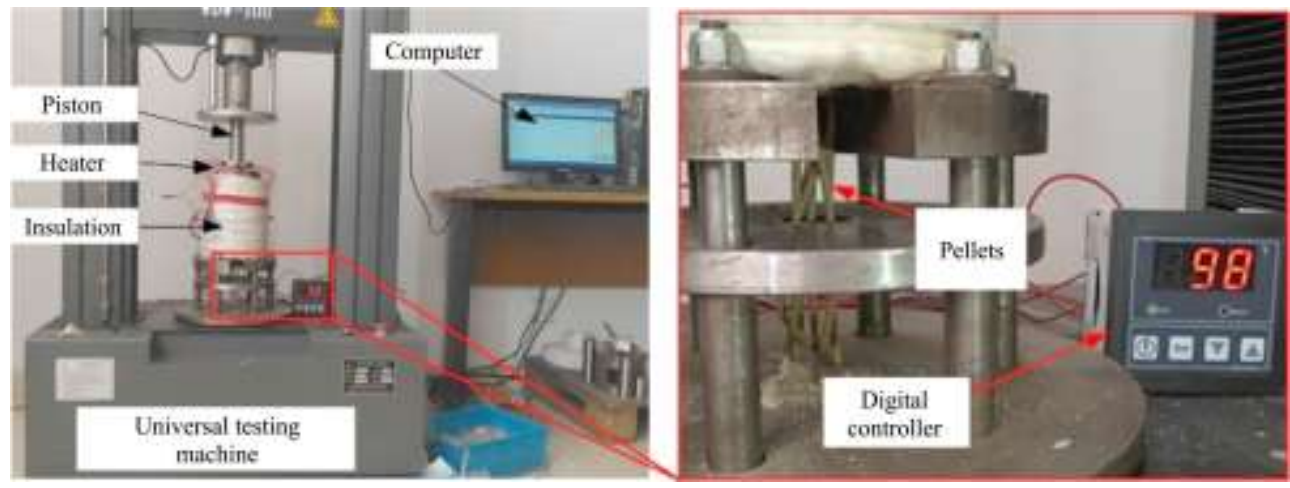

Figure 1 MPD experimental system

\subsection{Preparation of materials}

The diet formulations of animal feedstock used are shown in Table 1.

In this study, the effects of feedstock moisture content $\left(M_{\mathrm{cf}}\right)$, feedstock particle size $\left(S_{\mathrm{f}}\right)$, die temperature $\left(T_{\mathrm{d}}\right.$ representing the influence of temperature), compression speed $\left(V_{c}\right)$ on the pellet properties and compression force were experimentally investigated. Feedstocks of five different sizes were created by sieving with US series sieves $(8,12,16,20$, and 24 meshes). The sieve size only represented the five size levels rather than the actual size of the feedstock particles.

Table 1 Diet formulations (\%, as-is basis)

\begin{tabular}{cc}
\hline Ingredient & Content/\% \\
\hline Corn & 64 \\
Soybean meal & 29.9 \\
Soybean oil & 3.3 \\
Defluorinated phosphate & 1.4 \\
Limestone & 0.8 \\
Salt & 0.15 \\
Poultry premix & 0.25 \\
DL-Methionine & 0.07 \\
Coban & 0.08 \\
BMD & 0.05
\end{tabular}

The feedstock moisture content of each group was determined using a moisture analyzer (MA 45, Sartorius, Germany) at $105^{\circ} \mathrm{C}$ and then adjusted to $10 \%, 12 \%, 14 \%, 16 \%$ and $18 \%$ (w.b.) according to Equation (1) respectively. The feedstock after treatment was then sealed in plastic bags and kept for compression.

$$
m_{x}=m_{0} \frac{1-w_{0}}{1-w_{x}} \times 100 \%
$$

where, $m_{\mathrm{x}}$ is the final mass of feedstock after treatment, $\mathrm{g} ; m_{0}$ is the initial mass of feedstock before treatment, $\mathrm{g} ; w_{0}$ is the initial moisture content, $\% ; w_{x}$ is the desired moisture content, $\%$.

\subsection{Experimental method}

The structural integrity and physical properties of the pellet production may be affected by the combination of steam pressure, conditioning temperature, and material characteristics. Based on the MPD and RSM, the present study investigated the influences of processing parameters on pellet properties and established predictive models for compression force and pellet properties, such as pellet density $\left(\rho_{\mathrm{p}}\right)$, pellet tensile strength $\left(D_{\mathrm{p}}\right)$, pellet moisture content $\left(M_{\mathrm{cp}}\right)$. RSM is an effective statistical technique to build and optimize multifactor experimental models and to evaluate the effects of processing parameters on desirable responses ${ }^{[26-28]}$. Compression force, pellet density, pellet moisture content, and pellet tensile strength were responses, while feedstock moisture content and feedstock particle size, die temperature and extrusion speed were factors. Due to the small pellet size and low production rate, durability and bulk density tests which require a bulk quantity of pellets are unsuitable for pellets extruded from the MPD. In this study, the pellet qualities are represented by the pellet density, pellet moisture content, and pellet tensile strength.

In this work, the pelleting temperature is represented by die 
temperatures indirectly, and the temperature in the core of the compressed material is unknown. The tube and die were preheated and maintained to a specific temperature $\left(70^{\circ} \mathrm{C}, 80^{\circ} \mathrm{C}\right.$, $90^{\circ} \mathrm{C}, 100^{\circ} \mathrm{C}$ and $110^{\circ} \mathrm{C}$ ) by the digital controller during the pelleting process. This was consistent with the work of Zimonja et al. ${ }^{[29]}$ who suggested that the pelleting temperature should be in the range of $80^{\circ} \mathrm{C}-90^{\circ} \mathrm{C}$. The load speed of the piston was adjusted to a specified value $(5 \mathrm{~mm} / \mathrm{min}, 10 \mathrm{~mm} / \mathrm{min}, 15 \mathrm{~mm} / \mathrm{min}$, $20 \mathrm{~mm} / \mathrm{min}$, and $25 \mathrm{~mm} / \mathrm{min}$ ). Before the compression, a multi-hole die and piston were placed in the tube and heated to a specified and steady temperature. In each experimental run, $25 \mathrm{~g}$ feedstock adjusted to specified moisture content and particle size was loaded into the tube and then the pressing piston was placed into the tube. In order to raise the temperature to the die temperature approximately without evident moisture loss, the feedstock was kept between multi-hole die and piston for $90 \mathrm{~s}$. With the displacement of the piston at a certain speed, the feedstock was compacted and then forced to pass through the press channels, and the cylinder products were finally formed. Each pressing was replicated 3 times. During the compression process, the raw material particles were forced together and the interparticle bonding was created by the applying mechanical force. In the present study, the MPD was not equipped with a cutter, and thus the extruded pellets were longer. The schematic diagram and picture of the MPD are shown in Figure 2.

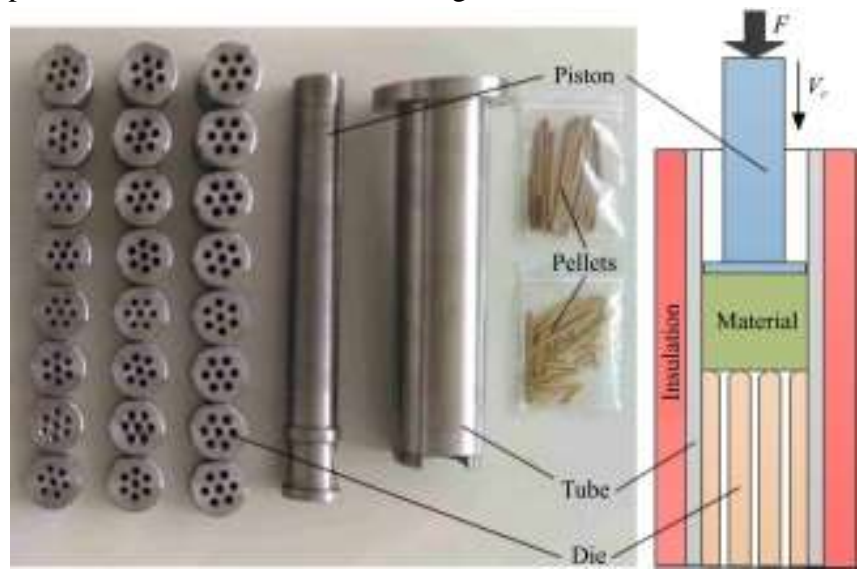

Figure 2 Schematic diagram and picture of the MPD

Pelleting experiments were conducted using the central composite design (CCD). The influences of the process parameters and material properties on the compression force and pellet properties were analyzed based on the analysis of variance (ANOVA). The coded levels and actual values of the process factors are shown in Table 2. To prevent being affected by moisture from the air, the pellets were cooled in ambient conditions for $30 \mathrm{~min}$ and then stored in sealed plastic bags until further tests were conducted.

Table 2 Experimental conditions tested for pelleting animal feed in a MPD

\begin{tabular}{ccccc}
\hline Coded levels & $M_{c f}$ & $S_{f}$ & $T_{d}$ & $V_{c}$ \\
\hline-2 & 10 & 8 & 70 & 5 \\
-1 & 12 & 12 & 80 & 10 \\
0 & 14 & 16 & 90 & 15 \\
1 & 16 & 20 & 100 & 20 \\
2 & 18 & 24 & 110 & 25 \\
\hline
\end{tabular}

\subsection{Compression force}

The information about processability can be represented by $F_{\text {out }}$ for pelleting and the yield stress of materials. $F_{\text {out }}$ represents the minimum pressure required to force the compressed materials to flow into and pass through the open-end cylindrical press channels at a certain speed. $F_{\text {out }}$ absented in most single pellet presses is co-varying with material properties and processing parameters in a MPD, consistent with the industrial pellet process. The sample materials were compressed at a specified compression speed until most materials were extruded from the press channels. The compression force-time curve based on the MPD is shown in Figure 3. The compression force can be used as a reference for the energy consumption of the pelleting process.

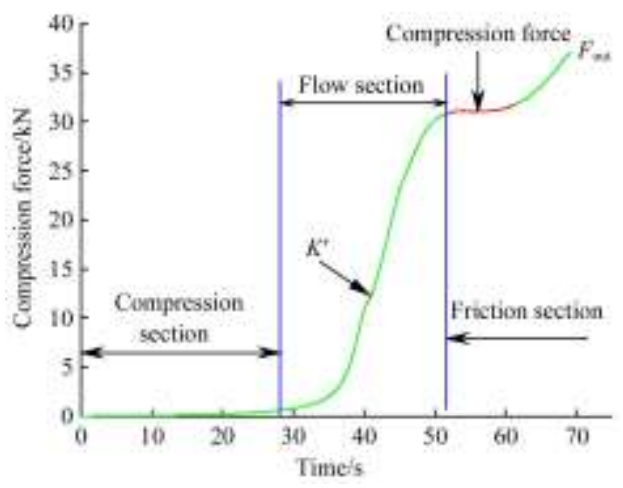

Figure 3 Compression force-time curve based on the MPD

The pelletization process can be divided into three sections ${ }^{[20,30]}$ : compression, flow and friction component corresponding to the three parts of the compression force-time curve in Figure 3. In the first section involving the process of material pre-compaction, some non-permanent elastic deformation of the material in the tube that lasts only as long as the pressure is applied could be induced during compaction, corresponding to the first part of the compression force-time curve. With the movement of the piston, the compression force increased slowly, and the raw material particles would be rearranged and stacked during the compression section. The flow component represents the energy required to force the compressed materials into the press channels as shown in the second part of the compression force-time curve. In this section, the compression force increased exponentially accompanied with elastic and plastic deformation of the particles. The material was forced to flow into the press channels at point $K^{\prime}$. As the press channels were filled with material, the compression force increased. The friction section involving the friction between the feedstock and die wall stands for the energy required to press the compressed material from inside to outside of the die, as presented in the stable part of compression curve. When the materials came out from press channels, the compression force kept steady and smooth until most materials were pressed out while the compression curve increased rapidly again. In this study, $F_{\text {out }}$ is determined by the valley of the friction part in the curve.

\subsection{Pellet density}

The pellet density was determined by mass and volume of granular pellet immediately after extruding the material from press channels and cooling. The two ends of granular pellet were smoothed with sandpaper. The pellet densities were calculated according to Equation (2) through measuring the mass, diameter, and length for at least 10 pellets using a Vernier caliper ${ }^{[31]}$.

$$
\rho_{p}=\frac{m}{V_{p}}
$$

where, $\rho_{p}$ is the pellet density, $\mathrm{kg} \cdot \mathrm{m}^{-3} ; m$ is the pellet mass, $\mathrm{kg} ; V_{p}$ is the pellet volume, $\mathrm{m}^{-3}$. 


\subsection{Pellet moisture content}

During the pelleting process, materials can dry up caused by the temperature of the tube and die. The pellet moisture content was determined by drying manually crushed pellets in a moisture analyzer (MA 45, Sartorius, Germany) at a temperature of $105^{\circ} \mathrm{C}$.

\subsection{Pellet tensile strength}

Pellet tensile strength is often used to evaluate the quality of a densified cylindrical pellet. Tensile strength is designed to simulate the pressure suffered by pellets in lower layer caused by upper layers during transportation and storage operations. The pellet tensile strength depends on cohesion force including capillary forces, mechanical interlocking forces of rough particle surfaces, electrostatic forces of feedstock particles, and cementing agent ${ }^{[32]}$. The larger particles in raw material improve mechanical interlocking and the finer particles increase the number of contact points between particles during the pelletization process. In this study, the sample pellet strength was determined by tensile strength test. The crushing force is defined as the maximum load of a single pellet located between two plates with a constant speed of $5 \mathrm{~mm} / \mathrm{min}$ before crushing. The schematic diagram of the tensile strength of pellet is shown in Figure 4. The data presented is an average of three measurements. The tensile strength $(\sigma)$ for cylindrical pellets was calculated by the following equation ${ }^{[32,33]}$.

$$
\sigma=\frac{2 F}{\pi D h}
$$

where, $\sigma$ is the tensile strength, $\mathrm{MPa} ; F$ is the crushing force, $\mathrm{N} ; D$ is the diameter, $\mathrm{m} ; h$ is the length of the sample pellet, $\mathrm{m}$.

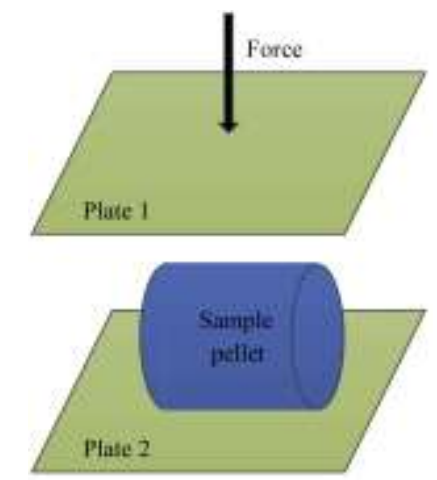

Figure 4 Schematic diagram of the tensile strength of pellet

\section{Results}

\subsection{Experimental results}

Results of the response variables are shown in Table 3. The cylindrical pellets produced by the MPD at different process conditions are shown in Figure 5.

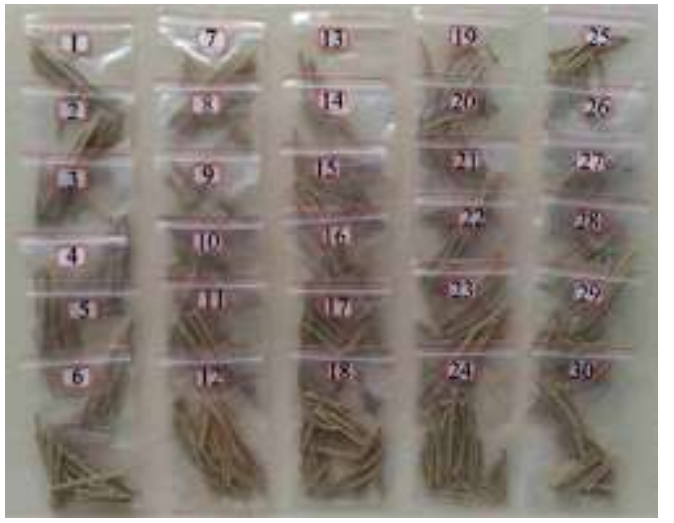

Figure 5 Pellets produced by a MPD at different process conditions
Table 3 Pelleting experimental data collected based on central composite design

\begin{tabular}{|c|c|c|c|c|c|c|c|c|}
\hline $\begin{array}{c}\text { Test } \\
\text { number }\end{array}$ & $\begin{array}{l}M_{\mathrm{cf}} \\
\left(\mathrm{x}_{1}\right)\end{array}$ & $\begin{array}{c}S_{\mathrm{f}} \\
\left(\mathrm{x}_{2}\right)\end{array}$ & $\begin{array}{c}T_{\mathrm{d}} \\
\left(\mathrm{x}_{3}\right)\end{array}$ & $\begin{array}{c}V_{\mathrm{c}} \\
\left(\mathrm{x}_{4}\right)\end{array}$ & $\begin{array}{l}F_{\text {out }} \\
/ \mathrm{kN}\end{array}$ & $\underset{/ \mathrm{kg} \cdot \mathrm{m}^{-3}}{\rho_{\mathrm{p}}}$ & $\begin{array}{l}M_{\mathrm{cp}} \\
1 \%\end{array}$ & $\begin{array}{c}D_{\mathrm{p}} \\
/ \mathrm{MPa}\end{array}$ \\
\hline 1 & 14 & 16 & 90 & 5 & 15.43 & 1227.65 & 10.87 & 2.69 \\
\hline 2 & 14 & 16 & 70 & 15 & 39.39 & 1254.77 & 12.44 & 1.82 \\
\hline 3 & 14 & 16 & 90 & 15 & 27.03 & 1226.04 & 11.07 & 2.38 \\
\hline 4 & 12 & 20 & 80 & 10 & 44.32 & 1267.58 & 10.72 & 2.3 \\
\hline 5 & 16 & 12 & 100 & 10 & 14.05 & 1172.15 & 11.84 & 2.38 \\
\hline 6 & 14 & 16 & 90 & 15 & 25.1 & 1226.83 & 10.98 & 2.37 \\
\hline 7 & 16 & 12 & 80 & 10 & 19.78 & 1217.45 & 13.35 & 2.41 \\
\hline 8 & 14 & 16 & 90 & 15 & 26.02 & 1222.52 & 10.86 & 2.43 \\
\hline 9 & 18 & 16 & 90 & 15 & 12.14 & 1173.23 & 14.59 & 2.14 \\
\hline 10 & 12 & 20 & 80 & 20 & 54.59 & 1269.52 & 10.89 & 1.97 \\
\hline 11 & 16 & 12 & 80 & 20 & 27.84 & 1206.26 & 13.19 & 2.01 \\
\hline 12 & 16 & 20 & 80 & 10 & 17.1 & 1211.66 & 13.14 & 2.36 \\
\hline 13 & 12 & 12 & 100 & 20 & 30.26 & 1249.43 & 10.42 & 2.12 \\
\hline 14 & 16 & 20 & 100 & 10 & 13.54 & 1182.47 & 12.21 & 2.45 \\
\hline 15 & 10 & 16 & 90 & 15 & 56.8 & 1315.35 & 9.21 & 2.02 \\
\hline 16 & 14 & 16 & 90 & 15 & 24.48 & 1239.75 & 11.24 & 2.42 \\
\hline 17 & 14 & 16 & 90 & 25 & 30.93 & 1199.32 & 11.53 & 2.09 \\
\hline 18 & 12 & 12 & 100 & 10 & 27.22 & 1258.76 & 9.82 & 2.46 \\
\hline 19 & 12 & 12 & 80 & 20 & 55.02 & 1260.86 & 10.66 & 1.96 \\
\hline 20 & 14 & 8 & 90 & 15 & 26.79 & 1234.92 & 11.54 & 2.39 \\
\hline 21 & 14 & 16 & 90 & 15 & 26.46 & 1224.19 & 11.19 & 2.33 \\
\hline 22 & 16 & 12 & 100 & 20 & 13.99 & 1175.77 & 12.99 & 2.31 \\
\hline 23 & 16 & 20 & 100 & 20 & 15.75 & 1167.53 & 12.65 & 2.32 \\
\hline 24 & 12 & 12 & 80 & 10 & 43.53 & 1270.34 & 10.58 & 2.28 \\
\hline 25 & 14 & 24 & 90 & 15 & 19.07 & 1214.88 & 12.15 & 2.42 \\
\hline 26 & 14 & 16 & 90 & 15 & 23.31 & 1231.56 & 11.13 & 2.33 \\
\hline 27 & 12 & 20 & 100 & 20 & 31.11 & 1245.34 & 10.67 & 2.14 \\
\hline 28 & 12 & 20 & 100 & 10 & 24.38 & 1241.56 & 10.03 & 2.35 \\
\hline 29 & 14 & 16 & 110 & 15 & 19.62 & 1203.45 & 10.38 & 2.25 \\
\hline 30 & 16 & 20 & 80 & 20 & 24.67 & 1184.57 & 13.27 & 2.04 \\
\hline
\end{tabular}

3.2 Regression analysis

The effects of the feedstock moisture content and feedstock particle size, die temperature and compression speed on the compression force, pellet density, pellet moisture content, and pellet tensile strength were determined. Respectively, ranges of the compression force, pellet density, pellet moisture content, and pellet tensile strength are 12.14-56.8 kN, $1167.53-1315.35 \mathrm{~kg} / \mathrm{m}^{3}$, 9.21\%-14.59\%, and 1.82-2.69 MPa. Higher compression forces and higher pellet density were observed at a lower moisture content of material ( $10 \%$ and $12 \%$, w.b.) and lower-to-medium die temperature $\left(80^{\circ} \mathrm{C}\right.$ and $\left.90^{\circ} \mathrm{C}\right)$. Higher feedstock moisture content $(16 \%, 18 \%$, w.b. $)$ and medium-to-higher die temperature $\left(90^{\circ} \mathrm{C}\right.$, $100^{\circ} \mathrm{C}$ ) resulted in lower pellet density. The highest and lowest pellet moisture content were observed at the highest and lowest material moisture content accordingly. Lower tensile strength values were observed at lower die temperature and medium-to-higher compression speed $(15 \mathrm{~mm} / \mathrm{min}, 20 \mathrm{~mm} / \mathrm{min}$ and $25 \mathrm{~mm} / \mathrm{min}$ ).

Analysis of variance (ANOVA) was then performed to remove the insignificant terms $(p>0.1)$ in the Design-Expert software. The response surface models corresponding to the response variables are shown in Table 4. All of the regression equations were statistically significant at $p<0.0001$ and $R^{2}>0.95$, indicating that the effects of process factors on the compression force and 
pellet properties were adequately described.

Table 4 Response surface models developed for compression force and pellet properties

\begin{tabular}{|c|c|c|}
\hline $\begin{array}{l}\text { Response } \\
\text { variable }\end{array}$ & Model & $R^{2}$ \\
\hline$F_{\text {out }}$ & $\begin{array}{l}y_{1}=544.30682-37.83513 x_{1}-0.22573 x_{2}-4.81408 x_{3}+ \\
3.53462 x_{4}+0.16384 x_{1} x_{3}-0.031837 x_{3} x_{4}+0.63635 x_{1}{ }^{2}+ \\
0.013041 x_{3}{ }^{2}\end{array}$ & 0.9782 \\
\hline$\rho_{\mathrm{p}}$ & $\begin{array}{l}y_{2}=1551.70325-28.26770 x_{1}-0.84244 x_{2}+0.89454 x_{3}+ \\
4.01099 x_{4}-0.15255 x_{1} x_{3}+0.88249 x_{1}^{2}-0.16685 x_{4}^{2}\end{array}$ & 0.9699 \\
\hline$M_{\mathrm{cp}}$ & $\begin{array}{l}y_{3}=30.03628-0.85375 x_{1}-0.37237 x_{2}-0.24531 x_{3}- \\
0.25721 x_{4}+0.0032625 x_{3} x_{4}+0.052522 x_{1}{ }^{2}+0.012271 x_{2}^{2} \\
+0.00087593 x_{3}^{2}\end{array}$ & 0.9793 \\
\hline$D_{\mathrm{p}}$ & $\begin{array}{l}y_{4}=-7.6925+0.53583 x_{1}+0.14996 x_{3}-0.097417 x_{4}+ \\
0.000775 x_{3} x_{4}-0.018438 x_{1}^{2}-0.00085 x_{3}^{2}\end{array}$ & 0.9544 \\
\hline
\end{tabular}

In Table $4, y_{1}$ to $y_{4}$ are the response variables $\left(F_{\text {out }}, \rho_{\mathrm{p}}, M_{\mathrm{cp}}, D_{\mathrm{p}}\right)$, $x_{1}$ to $x_{4}$ are the natural independent variables $\left(M_{\mathrm{cf}}, S_{\mathrm{f}}, T_{\mathrm{d}}, V_{\mathrm{c}}\right)$. Response surface plots were drawn for the compression force and pellet properties using the response surface model developed based on the experimental data to understand the interaction effects of the process factors. Each plot was drawn for two individual process factors by keeping other process factors at the center point of the central composite design. The results from the analysis of variance (ANOVA) of the experimental data indicated the significance of the linear, quadratic, and interaction terms of the process factors on the compression force and pellet properties.

\section{Discussion}

\subsection{Compression force}

On the basis of the regression models obtained in section 3.2, the contour plot of the compression force is shown in Figure 6, with the abscissa of the feedstock moisture content and the ordinate of die temperature. It indicates that there were significant interactions between the feedstock moisture content and die temperature. Higher temperature and moisture content led to a lower compression force due to the lubrication effect of protein, fat and moisture which can reduce the friction force through the press channels, and result in a low compression force. Further, higher temperatures will promote the lubrication effect. In contrast, lower temperature and moisture content will result in a high friction between the raw material and the press channel walls during the pelletizing process. The high friction will lead to high compression forces and consequently high energy consumption when up-scaling the process to a pellet mill. Figure 7 shows the compression force as a function of the die temperature and compression speed. Significant interactions between the die temperature and compression speed can be observed. The compression force increased with the decreasing of die temperature and the increasing of compression speed. Due to the promotion effects of temperature on lubrication, higher temperatures can lead to a lower compression force. Moreover, lower compression speed will extend the compression period for the material in the MPD.

\subsection{Pellet density}

Pellet density, representing the influence of bulk density in this paper, is an indicator of savings in transportation and storage. Figure 8 shows the effect of die temperature and the feedstock moisture content on the pellet density. The contour plot indicates that lower die temperature and lower feedstock moisture content maximized the pellet density. It is evident from the contour plot that as the moisture content increased, the pellet density decreased.
And this is because the void space between the raw material particles is occupied by amounts of water molecules, and cannot be expelled during the compression when increasing the feedstock moisture content ${ }^{[32,34]}$, which will result in increasing volume and decreasing density of the extruded pellets. On the other hand, the lubrication effect of increasing material moisture content decreases the compression force, leading to a lower pellet density. Higher pressure is commonly recognized as beneficial for decreasing the material porosity and formation of solid brides between the particles $^{[32,35]}$. Comparing Figures 6 and 8 , it is clear that the trend of the increase of pellet density and compression force with feedstock moisture content and die temperature followed an almost similar trend to one another. In addition, moisture evaporation from the surface is more rapidly in press channels at higher temperatures due to the contact with the hot die. This might be one of the reasons for the lower pellet density at higher die temperatures as observed during the pelleting process.

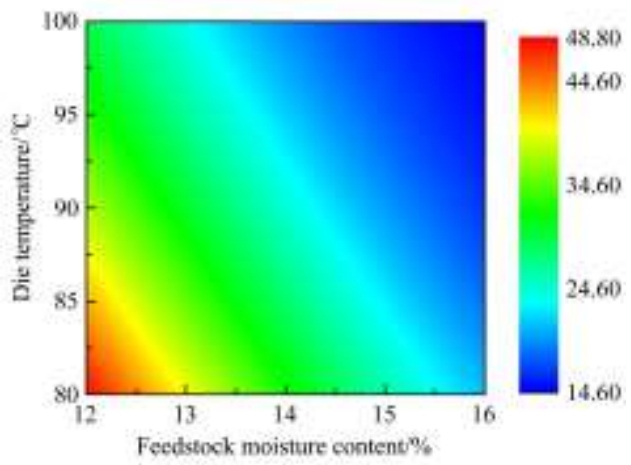

Figure 6 Effects of feedstock moisture content and die temperature on the compression force

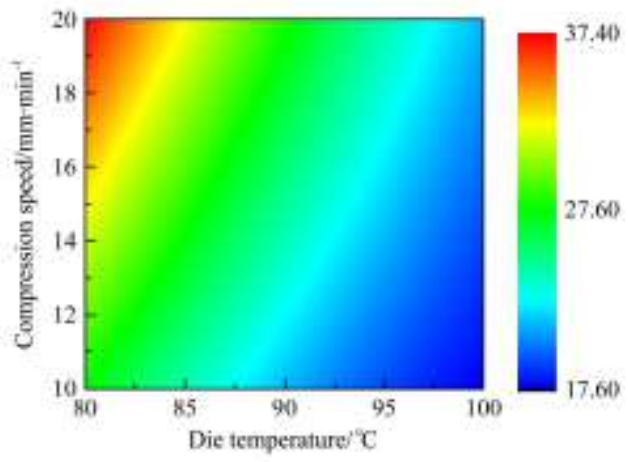

Figure 7 Effects of die temperature and compression speed on the compression force

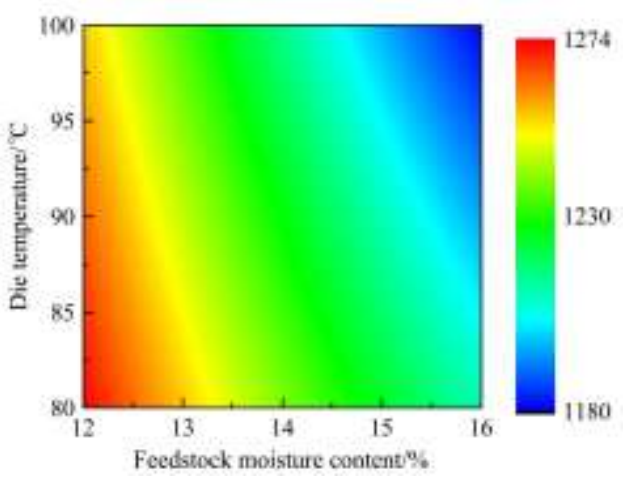

Figure 8 Effects of feedstock moisture content and die temperature on pellet density

\subsection{Pellet moisture content}

The pellet moisture contents, which were lower than those of the bulk feedstock increased linearly approximately with the 
increasing feedstock moisture content approximately. A contour plot (Figure 9) was drawn for the pellet moisture content with respect to the die temperature and compression speed. Figure 9 shows that the pellet moisture content decreases with increasing die temperature and decreasing compression speed. The reduction is mainly owing to the intensive evaporation of water attributed to the contact with the hot die during the pelletization process, especially at lower compression speeds, leading to a longer dwell time and higher die temperature leading to more evaporation of water.

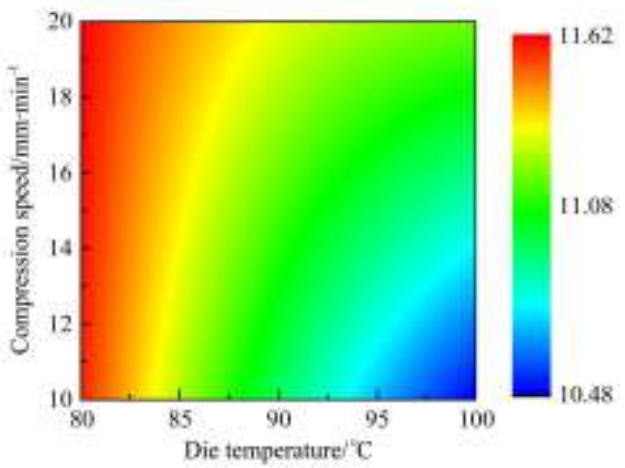

Figure 9 Effects of die temperature and compression speed on the pellet moisture content

Although higher moisture content decreased the energy consumption, excessively higher pellet moisture content might be one of the reasons for microbial degradation and mildew of the pellet products during storage.

\subsection{Pellet tensile strength}

Figure 10 shows the effects of the die temperature and compression speed on the pellet tensile strength. It is evident from the contour plot that as the compression speed increased, the pellet tensile strength decreased. The reduction is mainly due to the shortened dwell time in the press channels. Starch and protein, which can be softened with heating before and during compression, play an important role in the binding that occurs among the raw material particles during pelleting ${ }^{[16,17]}$. Solid bridges between the raw material particles in granular pellets are mainly formed after cooling. As the die temperature increased, the pellet tensile strength increased at first due to the promotion effect of binder and then decreased slightly due to the reduction of the compression force at higher die temperatures.

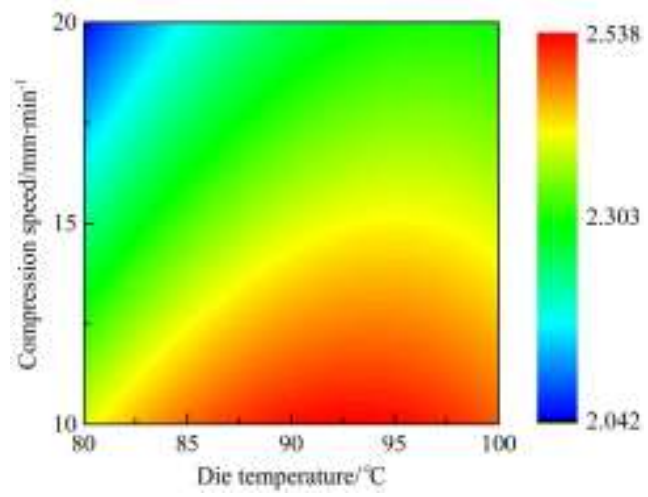

Figure 10 Effects of die temperature and compression speed on the pellet tensile strength

\section{Conclusions}

The influences of pelleting process factors on the compression force and pellet properties were investigated experimentally based on RSM and MPD, and the following conclusions were obtained:
Compression force depends on the process factors of pelletization, and it can be obtained based on the MPD.

Higher feedstock moisture contents (>15\% w.b.) and higher die temperatures $\left(>98^{\circ} \mathrm{C}\right)$ at the feedstock particle size of 15 mesh and compression speed of $15 \mathrm{~mm} / \mathrm{min}$ reduced the compression force down to less than $17 \mathrm{kN}$ and the pellet density to $1200 \mathrm{~kg} / \mathrm{m}^{3}$. High moisture and die temperature could help to reduce the compression force and thus reduced energy consumption. Higher die temperature and lower compression speed resulted in more intensive evaporation of water and lower pellet moisture content for safe storage. Lower die temperature and higher compression speed increased the compression force and resulted in lower strength pellets.

The combination of higher feedstock moisture content and die temperature at low compression speeds is a potential way to achieve lower compression force, lower energy consumption, and acceptable pellet density and tensile strength.

ANOVA of the experimental results indicated that feedstock moisture content, die temperature and compression speed influenced all the response variables including compression force and pellet properties. Response surface models developed for compression force and pellet properties with respect to the pelleting process factors adequately described the pelleting process $\left(R^{2}>\right.$ 0.95).

Parameter optimization based on the MPD can be useful and referenced for process adjustments, reduction of energy consumption, and improvement of pellet quality during industrial pelletizing.

\section{Acknowledgements}

We acknowledge that this work was supported by the Jiangsu Provincial Funds for Transformation of Scientific and Technological Achievements (BA2017081).

\section{[References]}

[1] Abdollahi M R, Ravindran V, Svihus B. Pelleting of broiler diets: An overview with emphasis on pellet quality and nutritional value. Animal Feed Science \& Technology, 2013; 179(1-4): 1-23.

[2] Cutlip S E. The effect of steam-conditioning practices on pellet quality and growing broiler nutritional value. Journal of Applied Poultry Research, 2008; 17(2): 249-261.

[3] Thomas M, van der Poel A F B. Physical quality of pelleted animal feed 1. Criteria for pellet quality. Animal Feed Science \& Technology, 1996; 61(1): 89-112.

[4] Svihus B, Zimonja O. Chemical alterations with nutritional consequences due to pelleting animal feeds: A review. Animal Production Science, 2011; 51(7): 590-596.

[5] Behnke K C. Feed manufacturing technology: Current issues and challenges. Animal Feed Science \& Technology, 1996; 62(1): 49-57.

[6] Johnson P, Cenkowski S, Paliwal J. Compaction and relaxation characteristics of single compacts produced from distiller's spent grain. Journal of Food Engineering, 2013; 116(2): 260-6.

[7] Lv M, Yan L, Wang Z, An S, Wu M, Lv Z. Effects of feed form and feed particle size on growth performance, carcass characteristics and digestive tract development of broilers. Animal Nutrition, 2015; 1(3): 252-255.

[8] Zimonja O, Svihus B. Effects of processing of wheat or oats starch on physical pellet quality and nutritional value for broilers. Animal Feed Science \& Technology, 2009; 149(3-4): 287-297.

[9] Tran Q D, Hendriks W H, van der Poel A F B. Effects of drying temperature and time of a canine diet extruded with a 4 or $8 \mathrm{~mm}$ die on physical and nutritional quality indicators. Animal Feed Science \& Technology, 2011; 165(3-4): 258-264.

[10] Naderinejad S, Zaefarian F, Abdollahi M R, Hassanabadi A, Kermanshahi $\mathrm{H}$, Ravindran V. Influence of feed form and particle size on performance, nutrient utilisation, and gastrointestinal tract development and 
morphometry in broiler starters fed maize-based diets. Animal Feed Science \& Technology, 2016; 215: 92-104.

[11] Abdollahi M R, Ravindran V, Wester T J, Ravindran G, Thomas D V. Effect of improved pellet quality from the addition of a pellet binder and/or moisture to a wheat-based diet conditioned at two different temperatures on performance, apparent metabolisable energy and ileal digestibility of starch and nitrogen in broilers. Animal Feed Science \& Technology, 2012; 175(3-4): 150-157.

[12] Holm J K, Henriksen U B, Hustad J E, Sørensen L H. Toward an understanding of controlling parameters in softwood and hardwood pellets production. Energy \& Fuels, 2006; 20(6):2686-2694.

[13] Wang Y, Wu K, Sun Y. Pelletizing properties of wheat straw blending with rice straw. Energy \& Fuels, 2017; 31(5): 5126-5134.

[14] Amerah A M, Quiles A, Medel P, Sánchez J, Lehtinen M J, Gracia M I. Effect of pelleting temperature and probiotic supplementation on growth performance and immune function of broilers fed maize/soy-based diets. Animal Feed Science \& Technology, 2013; 180(1-4): 55-63.

[15] Castrillo C, Mota M, van Laar H, Martín-Tereso J, Gimeno A, Fondevila $\mathrm{M}$ et al. Effect of compound feed pelleting and die diameter on rumen fermentation in beef cattle fed high concentrate diets. Animal Feed Science \& Technology, 2013; 180(1-4): 34-43.

[16] Thomas M, van Vliet T, van der Poel A F B. Physical quality of pelleted animal feed 3: Contribution of feedstuff components. Animal Feed Science \& Technology, 1998; 70(1): 59-78.

[17] Kaliyan N, Vance Morey R. Factors affecting strength and durability of densified biomass products. Biomass \& Bioenergy, 2009; 33(3):337-359.

[18] Draganovic V, van der Goot A J, Boom R, Jon J. Assessment of the effects of fish meal, wheat gluten, soy protein concentrate and feed moisture on extruder system parameters and the technical quality of fish feed. Animal Feed Science \& Technology, 2011; 165(3): 238-250.

[19] Segerström M, Larsson S H. Clarifying sub-processes in continuous ring die pelletizing through die temperature control. Fuel Processing Technology, 2014; 123(7): 122-126.

[20] Nielsen N P K, Gardner D J, Poulsen T, Felby C. Importance of temperature, moisture content, and species for the conversion process of wood residues into fuel pellets. Wood and Fiber Science, 2009; 41(4): 414-425

[21] Gilbert P, Ryu C, Sharifi V, Swithenbank J. Effect of process parameters on pelletisation of herbaceous crops. Fuel, 2009; 88(8): 1491-1497.

[22] Wongsiriamnuay T, Tippayawong N. Effect of densification parameters on the properties of maize residue pellets. Biosystems Engineering, 2015; 139 (November): 111-120.
[23] Holm J K, Henriksen U B, Wand K, Hustad J E, Posselt D. Experimental verification of novel pellet model using a single pelleter unit. Energy \& Fuels, 2007; 21(4): 2446-2449.

[24] Holm J K, Stelte W, Posselt D, Ahrenfeldt J, Henriksen U B Optimization of a Multiparameter Model for Biomass Pelletization to Investigate Temperature Dependence and to Facilitate Fast Testing of Pelletization Behavior. Energy \& Fuels, 2011; 25(8): 3706-3711.

[25] Mišljenović N, Čolović R, Vukmirović Đ, Brlek T, Bringas C S. The effects of sugar beet molasses on wheat straw pelleting and pellet quality. A comparative study of pelleting by using a single pellet press and a pilot-scale pellet press. Fuel Processing Technology, 2016; 144: 220-229.

[26] Tumuluru J S. Specific energy consumption and quality of wood pellets produced using high-moisture lodgepole pine grind in a flat die pellet mill. Chemical Engineering Research \& Design, 2016; 110: 82-97.

[27] Song X, Zhang M, Pei Z J, Wang D. Ultrasonic vibration-assisted pelleting of wheat straw: A predictive model for energy consumption using response surface methodology. Ultrasonics, 2014; 54(1): 305-311.

[28] Jha S K, Singh A, Kumar A. Physical characteristics of compressed cotton stalks. Biosystems Engineering, 2008; 99(2): 205-10.

[29] Zimonja O, Stevneb A, Svihus B. Nutritional value of diets for broiler chickens as affected by fat source, amylose level and diet processing. Canadian Journal of Animal Science, 2007; 87(4): 553-562.

[30] Stelte W, Nielsen N P K, Hansen H O, Dahl J, Shang L, Sanadi A R. Pelletizing properties of torrefied wheat straw. Biomass \& Bioenergy, 2013; 53(49): 105-112.

[31] Tumuluru J S. Effect of process variables on the density and durability of the pellets made from high moisture corn stover. Biosystems Engineering, 2014; 119(4): 44-57.

[32] Bazargan A, Rough S L, McKay G. Compaction of palm kernel shell biochars for application as solid fuel. Biomass \& Bioenergy, 2014; 70 : 489-497.

[33] Song B, Rough S L, Wilson D I. Effects of drying technique on extrusion-spheronisation granules and tablet properties. International Journal of Pharmaceutics, 2007; 332(1-2): 38-44.

[34] Berthold J, Rinaudo M, Salmeń L. Association of water to polar groups; estimations by an adsorption model for ligno-cellulosic materials. Colloids and surfaces A: Physicochemical and engineering aspects, 1996; 112(2): 117-129.

[35] Lai Z Y, Chua H B, Goh S M. Influence of process parameters on the strength of oil palm kernel shell pellets. Journal of Materials Science, 2013; 48(4): 1448-1456. 